\title{
Article \\ Sell Winners and Buy Losers? The Impact of Familiarity on Individual Investors' Decision-Making: Experimental Results
}

\author{
Vladislav Zhdanov ${ }^{1, *(1)}$ and Artem Simonov ${ }^{2}$ \\ 1 Higher School of Economics, 101000 Moscow, Russia \\ 2 Boston Consulting Group (Russia), 125047 Moscow, Russia; art.simonov@gmail.com \\ * Correspondence: vladislav.zhdanov@gmail.com; Tel.: +7-985-462-4590; Fax: +7-499-262-5742
}

Citation: Zhdanov, Vladislav, and Artem Simonov. 2021. Sell Winners and Buy Losers? The Impact of Familiarity on Individual Investors Decision-Making: Experimental Results. International Journal of Financial Studies 9: 47. https:// doi.org/10.3390/ijfs9030047

Received: 29 June 2021

Accepted: 27 August 2021

Published: 2 September 2021

Publisher's Note: MDPI stays neutral with regard to jurisdictional claims in published maps and institutional affiliations.

Copyright: (c) 2021 by the authors. Licensee MDPI, Basel, Switzerland. This article is an open access article distributed under the terms and conditions of the Creative Commons Attribution (CC BY) license (https:// creativecommons.org/licenses/by/ $4.0 /)$.

\begin{abstract}
Purpose: This article analyzes the influence of familiarity bias on respondents' decisionmaking process, using results from online experiments. Design/methodology/approach: A total of 255 research participants from post-Soviet countries completed 510 online tests that were presented in the form of investment games. In the games, the respondents were allowed to sell, buy, or hold two types of asset portfolios: familiar and unfamiliar assets. Findings: Holders of portfolios with familiar assets were 1.34 times more likely to be persistent in selling winners and holding losers and 1.10 times more likely to be persistent in buying fallen assets than holders of unfamiliar portfolios. Moreover, respondents who managed familiar assets tended to generate terminal result distributions with a kurtosis that was $27.8 \%$ higher than the distributions of those managing unfamiliar assets. Originality: Several academic studies have examined familiarity bias, the disposition effect, the positive feedback trading of individual investors, and risk-seeking trading; however, they investigated these topics separately. In the current study, we therefore created an online experiment to identify new aspects of investor behavior.
\end{abstract}

Keywords: behavioral finance; familiarity bias; reluctance to realize losses; riskier trading; positive feedback trading; heterogeneous trading

\section{JEL Classification: G110; G140; G150; G190}

\section{Introduction}

Previous studies have focused on the impact of familiarity bias on the disposition effect (Bulipopova et al. 2014). However, the respondents in these studies only succeeded in selling and holding assets that were enough to measure loss aversion. Moreover, individual investors can also buy assets. In the current study, we therefore created an online experiment to identify new aspects of investor behavior. The experiment design and methodology are explained later in this paper. This section discusses the essentials of behavioral finance and analyzes other aspects of the investor behavior under investigation.

The prospect theory by Kahneman and Tversky (1979) considered investor loss aversion as an anomaly resulting in the tendency to sell winners and hold losers. The disposition effect theory introduced by Shefrin and Statman (1985) incorporated this anomaly into its conceptual explanation of other investor irrationalities. Odean (1998) claimed that irrationality was the main aspect influencing market dislocation, causing investors to sell winners while avoiding losses.

The prospect theory is a wider concept compared to the disposition effect; therefore, we analyzed a few other phenomena that could be related to investors' decision-making in general.

The concept of familiarity bias, which was introduced by Graham (1955), is one of the most widely researched classical behavioral finance topics. Cao et al. (2011, p. 173) mention the "unfamiliarity premium" reflected in equilibrium stock prices. Other scientists have discussed the so-called home-country bias in foreign investment as a form of familiarity 
bias (Ke et al. 2009; Levis et al. 2016). Familiarity plays a pivotal role in allocating assets in a familiar milieu (Ke et al. 2009; Keloharju et al. 2012). Portfolio managers, for instance, often prefer to allocate funds to companies from their home states (Pool et al. 2012). Using individual Turkish investors' performance data, Tekçe et al. (2016) analyzed the strong correlation between familiarity bias, gender, age, and income.

Overconfidence is another bias that can affect investors' behavior. It may provoke investors to take risks, trade aggressively, and overestimate the importance of privately acquired information while disregarding public information (Rahma and Scalera 2019).

There is a subtle difference between familiarity and overconfidence. For instance, let us assume that portfolio managers choose to invest their clients' money in companies from their home countries. Is this a case of familiarity bias-Pool et al. (2012) argued that it is-or are such managers more aggressive and less sensitive to public information, thus showing overconfidence (as pointed out by Rahma and Scalera (2019))? Both kinds of bias can significantly influence investors.

Positive feedback trading is another concept involving asymmetry in terms of individuals trading, with a direct relation to our findings (Wan et al. 2016). We thus tested the hypothesis that familiarity bias could affect investors' decision-making, including buying preferences.

Our experiment analyzed one other essential manifestation of prospect theory-a statistically significant kurtosis difference that could be hypothesized to indicate the impact of familiarity and overconfidence biases due to its possible dependence on asset volatility in general (Rahma and Scalera 2019).

The current study, thus, used an experimental approach to analyze the impact of familiarity bias on individual investors' decision-making processes, including the disposition effect, buying preferences, and inclination to undertake riskier trading. As discussed earlier, several academic studies have examined familiarity bias, the disposition effect, the positive feedback trading of individual investors, and risk-seeking trading; however, they investigated these topics separately.

This paper argues that the following individual investor sentiment anomalies trigger familiarity bias:

- A reluctance to realize losses

- A persistence in terms of buying fallen assets

- $\quad$ Risk-seeking trading.

The paper structure has five sections. It starts from the Introduction (the current section), and Section 2. focuses on the materials (Section 2.1), dataset (Section 2.2), and methods (including verification; Section 2.3). There are three groups of results that can be found in Section 3: loss aversion, buying preferences, and risk-seeking (Sections 3.1-3.3, respectively). Section 4 . includes the study's discussion, and Section 5. concludes the paper. The reference list is located at the end of this paper in alphabetical order.

\section{Materials, Dataset, and Methods}

\subsection{Materials}

Participation in this study was voluntary. There was no psychological or financial risk for the study participants, and their personal information was not used. We followed the appropriate ethical codes of the Higher School of Economics.

We created a website (http:// finance2.z-marketing.ru, accessed on 13 December 2020), which housed our trading simulator. Every respondent who outperformed the experimental market was rewarded with money (which was paid out from the researchers' private funds), and the asset prices were changed randomly to motivate respondents. According to our analysis of visitors' IP addresses, most website visitors, both male and female, were Russian speakers from Russia, Ukraine, and other post-Soviet countries. This respondent distribution can be attributed partly to the fact that our website was publicized by a top Ukrainian social network influencer who promoted experimental websites. This Ukrainian influencer's audience was not limited to Ukraine; his Russian-language blog was ranked first and forty-third in Ukraine and the world, respectively (according to recent 
livejournal.com statistics, accessed on 1 June 2021). Thus, the experiment participants were Russian speakers from around the world. Respondents were also recruited through the current study authors' Facebook friend list.

The familiar assets portfolio (Figure 1) consisted of well-known commodities: grain, corn, gold, oil, sugar, tea, coffee, and coal. We decided to utilize commodities to avoid the dissemination of misinformation regarding blue chips' management among the participants; this helped to ensure that all our respondents remained keen on the assets in the portfolios. For example, we assumed that disseminating information suggesting that certain Russian blue chips were showing negative trading trends to our respondents on social networks could potentially misinform real investors. Additionally, we used Russian as the communication language to increase familiarity.

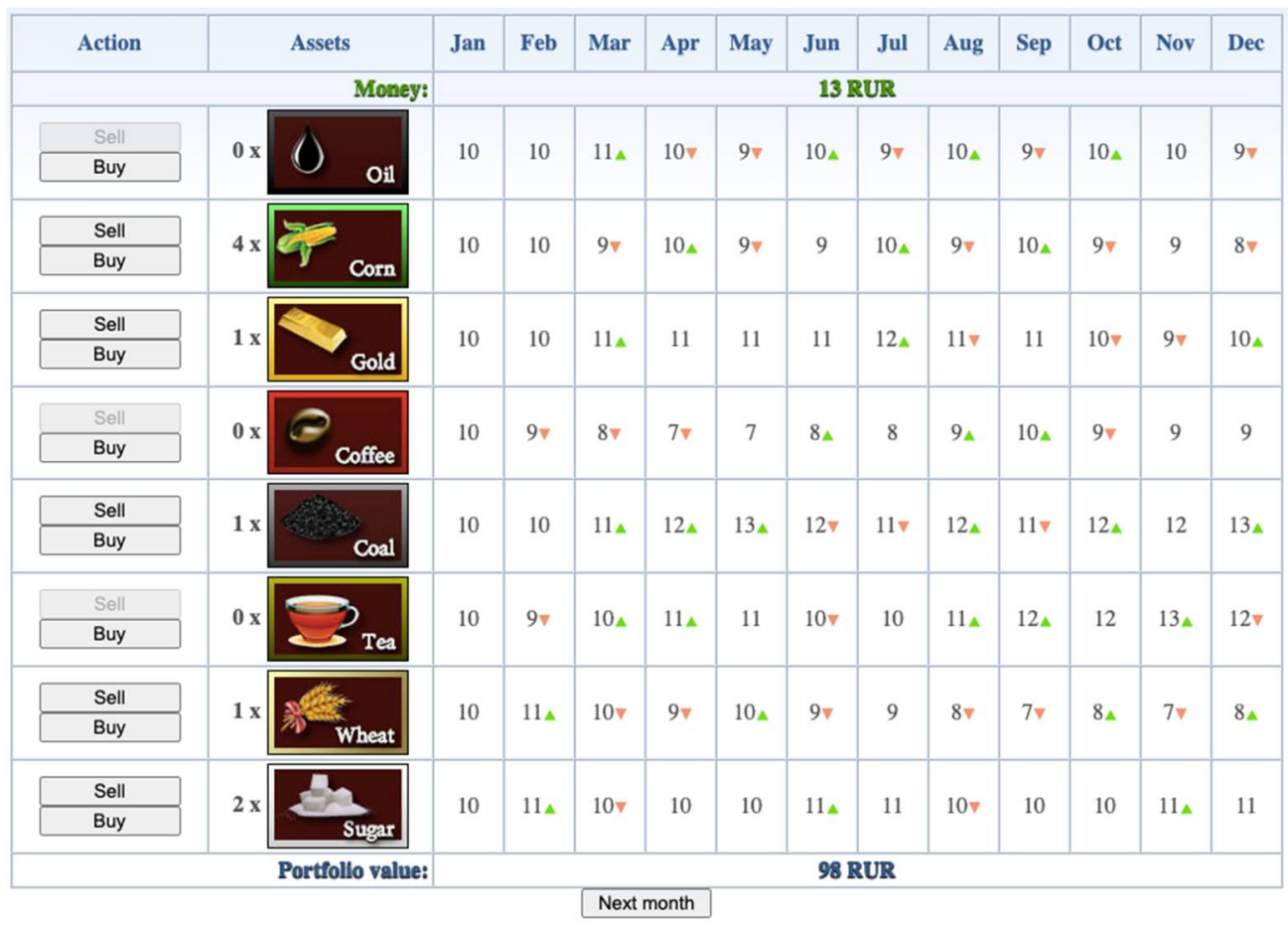

Figure 1. Familiar experimental portfolio at the end of the first session.

Moreover, we used rubles (RUB) to simplify the final transfer to the winning respondents. However, a significant number of non-residential Russian-speaking respondents (residential status determined based on the IP data) preferred to use other currencies for PayPal transfers. Additionally, in previous experiments (Bulipopova et al. 2014), the US dollar was used in financial transactions, and payments to winners often slightly strained the experiment budget. Thus, we chose to conduct transactions using RUB ( $\$ 1$ is equal to 72.5 RUB [as of June 2021]).

The unfamiliar portfolio contained assets that were labeled with a randomly chosen combination of the three letters X, Y, and Z (for example, see ZXX or YXZ [Supplementary Scheme S1]). The 12 months from January to December were featured at the top of the table (to the right of the asset's column head). The game started in January; all respondents had eight assets, each of which was worth 10 RUB. They also had 20 RUB in cash, and the initial total value was always 100 RUB. Sell and Buy buttons were located on the left-hand side of the table. The "total value" refers to the sum of all asset values, and it appears in the bottom row. This total value changed during every experimental month.

The trading rules, as explained on the website, were as follows:

Each respondent can only play the game once and must trade both familiar and unfamiliar portfolios, each of which is chosen for them randomly.

- The initial price of each of the eight assets is 10 RUB. 
- The initial deposit is 20 RUB.

- $\quad$ The price variation is 1 RUB (upward or downward).

- The trading process for each asset involves 11 rounds of price fluctuations (from February to December with January as the initial point).

- $\quad$ Respondents can sell, buy, or hold assets (i.e., respondents are allowed to trade during the experiment actively).

A specially constructed synthetic stochastic process was used for establishing the price generation process. We established an algorithm for generating random price increments (either +1 or -1 ) for every asset during every step of the process. This algorithm's distinctive feature was that it generated negatively correlated price increments for every randomly chosen pair of assets during every step of the process. We obtained a portfolio of assets that maintained a constant value for all assets over time (if a respondent did nothing, the portfolio remained at 100 RUB during every month of the experiment). However, the investor must make some effort and undergo a certain learning curve to understand the process. Arguably, one wealth-maximizing strategy for this type of portfolio involves allowing asset retention in higher concentrations (i.e., avoiding significant diversification), cutting losses quickly, and holding profitable trades for as long as possible.

We analyzed the terminal financial returns data to process the results (i.e., each respondent's results for both familiar and anonymous portfolios). We emphasized that each respondent, who was managing two types of portfolios (familiar and unfamiliar assets), had the opportunity to win real money. Random distribution was used to determine the type of portfolio that a respondent had to manage first; this helped to maintain the same level of uncertainty among all respondents.

\subsection{Dataset}

The dataset consists of the results of 510 online tests that were completed by 255 Russianspeaking respondents around the world. These results included financial performance- how many RUB a respondent won/lost, the number of transactions that were made by the respondents, and the respondents' unique PayPal or other account tags to transfer real money to them if they won.

\subsection{Verification}

We gathered results from all the respondents; these results can be viewed on http: / / finance2.z-marketing.ru/results.html (accessed on 1 August 2021). Sensitive personal information, including contact information and IP addresses, that was present in the results was concealed and made confidential.

We used Welch's two-sample t-test to analyze both loss aversion and buying anomalies in Sections 3.1 and 3.2, respectively; additional bootstrapping was used for riskier trading (Section 3.3) and to check for statistical differences between the estimated experiment metrics of familiar and unfamiliar portfolios (Horowitz 2019). To analyze the risk-seeking trading (Section 3.3), we used the standard procedure for resampling with replacement; generated 100,000 subsamples of investigated metrics; calculated the mean, standard deviation, and kurtosis for every sub-sample; and then implemented Welch's two-sample t-test to accept or reject the statistical equality hypothesis. The analysis was executed using the $\mathrm{R}$ programming language.

\section{Results}

\subsection{Loss Aversion}

This study primarily aimed to confirm the following hypothesis: holders of unfamiliar assets experience less reluctance regarding realizing losses (Bulipopova et al. 2014). To measure the disposition effect, we used the original Barber et al. (2007) methodology, which was also described and published in Bulipopova et al. (2014): 
(a) We calculated all Paper Gains (or Losses) by multiplying net profits/losses for one position (e.g., Grain in familiar assets, Figure 1) per month (e.g., March, -1 RUB) while considering the total amount of this stock in the given portfolio.

(b) We summarized each month's results into two separate columns-one each for Paper Gains and for Paper Losses-to arrive at separate Paper Gains (PG) and Paper Losses (PL).

(c) Next, we calculated the Realized Gains/Losses (RG/RL) by multiplying the Gains/Losses of each asset's position by the total assets sold by the respondents.

(d) We calculated the Proportion of Gains/Losses Realized (PGR or PLR) as follows: PGR $=R G /(R G+P G)$ and PLR $=R L /(R L+P L)$

(e) To find the average differences between PGR and PLR (AVG (PGR - PLR)) for both the familiar and unfamiliar portfolios, we used the results mentioned in point (d).

(f) $\quad$ AVG $(\text { PGR }- \text { PLR })^{\text {Familiarity }}=\left\{(\text { PGR }- \text { PRL })^{\text {Grain }}+(\text { PGR }- \text { PLR })^{\text {Oil }}+\ldots+(\right.$ PGR PLR) $)^{\text {Corn }} / 8$.

(g) A similar formula was used to find AVG (PGR - PLR) for unfamiliar portfolios.

We found that reluctance to realize losses was 1.34 times higher among holders of the familiar portfolios compared to those with unfamiliar portfolios: AVG (PGR - PLR) was $3.61 \%$ and $2.69 \%$ for familiar and unfamiliar portfolios, respectively (Table 1 ).

Table 1. Experimental results.

\begin{tabular}{|c|c|c|c|c|}
\hline Portfolio Type & $\begin{array}{l}\text { Number of } \\
\text { Respondents }\end{array}$ & $\begin{array}{c}\text { AVG (PGR }- \text { PLR) } \\
\text { (Selling Winners) } \\
p \text {-Value }<7.7 \times 10^{-3}\end{array}$ & $\begin{array}{c}\text { AVG (PBR }- \text { PBF) } \\
\text { (Buying Losers) } \\
p \text {-Value }<0.8 \times 10^{-3}\end{array}$ & $\begin{array}{c}\text { Kurtosis Means } \\
\text { (Risk-Seeking) } \\
p \text {-Value }<2.2 \times 10^{-16}\end{array}$ \\
\hline Unfamiliar & 255 & $2.69 \%$ & $-3.31 \%$ & 1.85 \\
\hline Familiar & 255 & $3.61 \%$ & $-3.63 \%$ & 2.56 \\
\hline
\end{tabular}

AVG (PGR - PLR): The average difference between Proportion of Gain Realized (PGR) and Proportion of Losses Realized (PLR). A negative difference means that respondents prefer selling more winners than losers in terms of assets' price fluctuations. AVG (PBR - PBF): The average difference between Proportion of Bought Raised assets (PBR) and Proportion of Bought Fallen assets (PBF). A negative difference means that respondents prefer buying losers rather than winners in terms of assets' price fluctuations. Under kurtosis, we understand the concept of "excess kurtosis". In a normal distribution, the value of kurtosis is zero, and the same statement is true for the distribution of terminal financial returns. A positive value of kurtosis of returns is an important indicator of riskier trading-the higher the kurtosis of terminal financial returns is, the more risk-seeking trading is observed, and vice versa.

I. We used Welch's two-sample t-test to reject the null hypothesis; the brief results of our calculation were as follows:

When the $p$-value equals $0.00773639(p(x \leq \mathrm{T})=0.996132)$, the probability of a type 1 error (rejecting a correct $\left.\mathrm{H}_{0}\right)$ occurring is small or $0.007736(0.77 \%)$. The average for the unfamiliar portfolios was not equal to the average for the familiar portfolio. Thus, the difference between the average of the unfamiliar and familiar samples was large enough to be statistically significant.

\subsection{Persistence in Terms of Buying Fallen Assets}

To evaluate the respondents' buying preferences, we modified the methodology used by Barber et al. (2007), which was mentioned in the previous section. The first two points $(\mathrm{a} \& \mathrm{~b})$ are similar:

$(a, b)$ We derived the paper gains/losses in the same way as in Section 3.1.

(c) Next, we calculated Bought Raised/Fallen (BR/BF) by multiplying the raised/fallen values for each asset's position by the total assets bought by the respondents.

(d) We calculated the Proportion of Bought Raised/Fallen (PBR/PBF) assets as follows:

$$
\mathrm{PBR}=\mathrm{BR} /(\mathrm{BR}+\mathrm{PG}) \text { and } \mathrm{PBF}=\mathrm{BF} /(\mathrm{BF}+\mathrm{PL})
$$

(e) To find the average differences between PBR and PBF for both the familiar and unfamiliar portfolios, we used the results mentioned in point (d).

$$
\mathrm{AVG}(\mathrm{PBR}-\mathrm{PBF})^{\text {Familiarity }}=\left\{(\mathrm{PBR}-\mathrm{PBF})^{\mathrm{Grain}}+(\mathrm{PBR}-\mathrm{PBF})^{\mathrm{Oil}}+\ldots+(\mathrm{PBR}-\mathrm{PBF})^{\mathrm{Corn}}\right\} / 8 .
$$


(f) We used a similar formula to find AVG (PBR-PBF) for unfamiliar portfolios. Our findings were as follows:

i. $\quad$ All respondents persisted in buying fallen assets. Based on positive feedback performance, this anomaly could be considered controversial with the classical trading approach (Wan et al. 2016). The respondents' buying patterns were as follows: $42 \%$ (3121) assets after fall 31\% (2305) assets when the price was not changing $27 \%$ (1962) assets after a rise

ii. The holders of familiar portfolios were 1.10 times more persistent in terms of buying fallen assets compared to holders of unfamiliar ones (see Table 1).

iii. Welch's two-sample t-test was conducted to reject the null hypothesis; the brief results of our calculations were as follows: When $p$-value equals 0.000769402 $(p(x \leq \mathrm{T})=0.999615)$, the probability of a type 1 error (rejecting a correct $\left.\mathrm{H}_{0}\right)$ occurring is small: $0.000769(0.077 \%)$. The average for the unfamiliar portfolios was not equal to the average for the familiar portfolios. Thus, the difference between the average of the unfamiliar and familiar samples is large enough to be statistically significant.

\subsection{Risk-Seeking Trading: Kurtosis of Terminal Financial Returns}

Recent research (Bulipopova et al. 2014) suggests that trading unfamiliar portfolios is another property of familiarity and overconfidence biases. In this case, the respondents' trading was characterized by lower tail risks (i.e., the financial return distributions for unfamiliar portfolios tend to have thinner tails). However, the same respondents tended to manage familiar portfolios in a risky manner based on their confidence regarding these assets.

The kurtosis value was 2.56 for familiar portfolios and 1.85 for unfamiliar portfolios (see Table 1); this translates to $27.8 \%$ lower tails for trading unfamiliar portfolios. To the best of our knowledge, this phenomenon has never been investigated using a trading simulation before.

We used the bootstrapping procedure mentioned by Horowitz (2019). Welch's twosample t-test rejected the null hypothesis at the $1 \%$ level. It showed a statistical difference in the kurtoses for familiar and unfamiliar portfolios, with $p$-value $<2.2 \times 10^{-16}$.

The findings of this analysis process are summarized in Table 1.

\section{Discussion}

This study focused on three different manifestations of investor sentiment anomalies: disposition effect, buying preferences, and risk-seeking trading.

First, we confirmed the hypothesis of Bulipopova et al. (2014): a familiarity bias reinforces individual investors' reluctance to realize losses. We upgraded the online experimental engine to add one more action for respondents-buying. Thus, the experiment conditions were modified to reflect real market conditions. Despite changing experimental conditions, the reluctance to realize losses observed in Bulipopova et al. (2014) and that in this study experiment were comparable-2.29\% and $2.69 \%$ versus $5.01 \%$ and $3.61 \%$ for unfamiliar and familiar portfolios, respectively. In our experiment, this difference was modest compared to the results obtained by Bulipopova et al. (2014) - that is, 1.34 and 2.19 times, respectively; however, the difference was still statistically significant.

Second, by adding the option "to buy" in the experiment, we identified a new investor anomaly, which was correlated with familiarity bias; our respondents who managed familiar portfolios were 1.10 times more persistent in terms of buying fallen assets compared to the holders of unfamiliar ones. Moreover, persistency in buying fallen assets was common among all respondents $-42 \%$ of all assets were bought when prices fell, and only $27 \%$ were bought when prices rose (the other $31 \%$ were bought when there was no price fluctuation). These findings could be valuable for analyzing the practical aspects of a positive feedback trading strategy. As indicated, most individuals tended not to intuitively buy winners under the uncertain conditions that were achieved in our experiments. However, individuals preferred to buy losers, especially when the assets were familiar to them. In our 
experiment, the managers of familiar portfolios bought losers 1.10 times more frequently than did the holders of unfamiliar portfolios.

Finally, we found a correlation between familiarity and risk-seeking trading. We measured this as the difference between the distributions of trading performance resultsthe kurtosis for familiar assets was 1.38 times higher than that for unfamiliar ones. Thus, familiarity caused individuals to carry out trade transactions characterized by higher risks.

Furthermore, there are other manifestations of individual investors' irrationality. One example is personality traits, which were analyzed by researchers such as Lai (2019), Kleine et al. (2016), and Tauni et al. (2015); these authors showed that personality also has a significant impact on individual investors' behavior. Taking this into consideration, we "switched off" the impact of respondents' personality to allow all participants to manage both types of portfolios as was mentioned above in Section 2.1.

\section{Conclusions}

Our study confirmed the hypothesis that familiarity bias directly affects three investor sentiment anomalies: loss aversion, buying preferences, and risk-seeking trading. This can be verified by future researchers who wish to repeat our approach. Holders of unfamiliar assets were 1.34 times less likely to be reluctant to realize losses and 1.10 times less likely to be persistent in buying fallen assets compared to those managing familiar assets. It is worth noting that the experiment respondents held both kinds of assets. Each respondent participated in the experiment twice-as a holder of familiar assets and then unfamiliar ones-and the order in which the portfolios were presented was randomized, to prevent any distortions in the results. We also observed that trading in unfamiliar assets resulted in respondents taking lower risks. This finding may have important implications with regard to risk management-both for private and institutional investors.

We hope our findings can be a contribution to the prospect theory field, particularly in terms of showing how familiarity can influence investor performance under experimental conditions. To highlight all our experimental results, we might as well use a term from Cao et al. (2011) — the "unfamiliarity premium"; this concept implies that familiarity bias reduces individual investors' trading performance.

In future research, we believe it would also be interesting to focus on other biases that could affect investors. For instance, an investigation of the anchoring bias could offer in-depth analysis experimentally. When we investigated our experimental data, we found that, from among all the familiarity assets, respondents' top three assets were sugar, coffee, and tea; coal was the last one in terms of trading anomalies. We found a significant divergence in the familiar portfolio between "everyday" commodities such as sugar, coffee, and tea and "industrial" ones such as coal, oil, and even gold. Although our respondents were familiar with gold and coal, other biases, such as anchoring, affected their decisions. We are also open to the possibility of further modifying our online engine, so that to enable us to add short selling for the participants, and thus be able to one more time check the existing findings and possibly get new ones.

Supplementary Materials: The following are available online at https:/ /www.mdpi.com/article/10 .3390/ijfs9030047/s1, Scheme S1: Example of an unfamiliar portfolio.

Author Contributions: All authors contributed equally. All authors have read and agreed to the published version of the manuscript.

Funding: Our research did not receive any specific grant from funding agencies in the public, commercial, or not-for-profit sectors.

Institutional Review Board Statement: Not applicable.

Informed Consent Statement: Not applicable.

Data Availability Statement: http:/ / finance2.z-marketing.ru/results.html (accessed on 1 August 2021). 
Acknowledgments: We would like to express our sincere gratitude to Alexander Larin and Lukas Andrzejewski for the priceless support of our research.

Conflicts of Interest: The authors declare that they have no known competing financial interest or personal relationship that could appear to have influenced the work reported in this paper.

\section{References}

Barber, Brad M., Yi-Tsung Lee, Yu-Jane Liu, and Terrance Odean. 2007. Is the aggregate investor reluctant to realise losses? Evidence from Taiwan. European Financial Management 13: 423-47. [CrossRef]

Bulipopova, Ekaterina, Vladislav Zhdanov, and Artem Simonov. 2014. Do investors hold that they know? Impact of familiarity bias on investor's reluctance to realize losses: Experimental approach. Finance Research Letters 11: 463-69. [CrossRef]

Cao, H. Henry, Bing Han, David Hirshleifer, and Harold H. Zhang. 2011. Fear of the unknown: Familiarity and economic decisions. Review of Finance 15: 173-206. [CrossRef]

Graham, Benjamin. 1955. The intelligent investor. Journal of Finance 10: 406-7. Available online: https://www.jstor.org/stable/2976900 (accessed on 30 June 2021).

Horowitz, Joel L. 2019. Bootstrap methods in econometrics. Annual Review of Economics 11: 193-224. [CrossRef]

Kahneman, Daniel, and Amos Tversky. 1979. Prospect theory: An analysis of decision under risk. Econometrica 47: 263-92. [CrossRef]

$\mathrm{Ke}$, Dongmin, Lilian Ng, and Qinghai Wang. 2009. Home bias in foreign investment decisions. Journal of International Business Studies 41: 960-79. [CrossRef]

Keloharju, Matti, Samuli Knüpfer, and Juhani Linnainmaa. 2012. Do investors buy what they know? Product market choices and investment decisions. Review of Financial Studies 25: 2921-58. [CrossRef]

Kleine, Jens, Niklas Wagner, and Tim Weller. 2016. Openness endangers your wealth: Noise trading and the big five. Finance Research Letters 16: 239-47. [CrossRef]

Lai, Cheng-Po. 2019. Personality traits and stock investment of individuals. Sustainability 11: 5474. [CrossRef]

Levis, Mario, Yaz Gülnur Muradoǧlu, and Kristina Vasileva. 2016. Home bias persistence in foreign direct investments. European Journal of Finance 22: 782-802. [CrossRef]

Odean, Terrance. 1998. Are investors reluctant to realize their losses? Journal of Finance 53: 1775-98. [CrossRef]

Pool, Veronika K., Noah Stoffman, and Scott E. Yonker. 2012. No place like home: Familiarity in mutual fund manager portfolio choice. Review of Financial Studies 25: 2563-99. [CrossRef]

Rahma, Ben Naya, and Francesco Scalera. 2019. Financial market anomalies and behavioral biases: Implications of overconfidence bias. Paper present at European Proceedings of Social \& Behavioral Sciences: Joint Conference 14th ISMC and 8th ICLTIBM-2018, Prague, Czechia, 12-14 July 2018; Edited by M. Jaworski, M. H. M. Hanafiah, J. A. Kumar and M. Sanugam. Bari: Future Academy, pp. 257-69. [CrossRef]

Shefrin, Hersh, and Meir Statman. 1985. The disposition to sell winners too early and ride losers too long: Theory and evidence. Journal of Finance 40: 777-90. [CrossRef]

Tauni, Muhammad Zubair, Hong Xing Fang, Zia-ur-Rehman Rao, and Salman Yousaf. 2015. The influence of investor personality traits on information acquisition and trading behavior: Evidence from Chinese futures exchange. Personality and Individual Differences 87: 248-55. [CrossRef]

Tekçe, Bülent, Neslihan Yılmaz, and Recep Bildik. 2016. What factors affect behavioral biases? Evidence from Turkish individual stock investors. Research in International Business E Finance 37: 515-26. [CrossRef]

Wan, Die, Weiyi Liu, Junbo Wang, and Xiaoguang Yang. 2016. Asymmetries of positive feedback trading in individual stocks: Evidences from China. Journal of Management Science \& Engineering 1: 3-27. [CrossRef] 